\title{
Notas para The Waste Land: T. S. Eliot e a máquina literária
}

\author{
Notes on The Waste Land: T. S. Eliot and the literary machine \\ André Cechinel \\ Universidade do Extremo Sul Catarinense - Criciúma - Santa Catarina - Brasil
}

$-\diamond$

Resumo: Este artigo propõe-se a investigar o suposto papel explicativo atribuído às notas que T. S. Eliot acrescentou ao poema The Waste Land quando de sua publicação. Para tanto, o texto volta a sua atenção, em particular, para três das várias observações em que o poeta expõe as referências por ele consultadas e referidas nos versos, isso com o intuito de verificar se de fato há um esclarecimento interpretativo prestado ao poema graças à inclusão das notas. Em linhas gerais, o choque entre os versos de The Waste Land e as notas autorais provoca um impasse que aciona o que aqui chamamos de uma "máquina literária" produtora de teses. Essa máquina, compreendida a partir de seu mecanismo estruturante, não só recusa a sugestão de que o entendimento do poema decorre da decodificação apropriada das fontes, como também produz um efeito plural responsável por desestabilizar a hierarquia classicista e canônica que a crítica literária por décadas viu ali instalada.

Palavras-chave: Eliot; Notas; Interpretação

\begin{abstract}
This paper intends to investigate the alleged explicative role assigned to the notes T. S. Eliot added to the poem The Waste Land when it was published. To this end, the text turns its attention, in particular, to three of the several observations in which the poet exposes the references he consulted and referred to in his lines. The purpose is to check whether there is in fact an interpretative clarification provided to the poem thanks to the notes. In general, the clash between the lines of the poem and the author's notes triggers an impasse that activates what we call here a "literary machine" that produces different theses. This machine, read from the perspective of its structuring mechanism, not only refuses the suggestion that the understanding of the poem results from the correct reading of its sources, but also produces a plural effect responsible for destabilizing the classicist and canonical hierarchy that literary criticism for decades saw there installed.
\end{abstract}

Keywords: Eliot; Notes; Interpretation

\section{Introdução}

Um rápido estudo da recepção crítica de The Waste Land [1922] desde sua publicação prova que, para além das temáticas ali comumente reconhecidas - e via de regra associadas a um decadentismo pós-guerra -, os versos de T. S. Eliot nos lançam a uma rede intertextual que parece impor ao leitor um procedimento de leitura como que incontornável, a saber, a identificação das fontes. Nesse sentido, mais que voltar a atenção ao seu funcionamento interno, uma leitura correta do poema demandaria a solução de um problema de origem: quais as referências que Eliot consultou para a composição de seus versos, ou ainda, por trás de sua superfície mais imediata, o que The
Waste Land oculta quanto às suas verdadeiras referências? Em suma, entender o que o poema "diz" significaria pronunciar-se sobre um silêncio maior, sobre aquilo que não se revela de pronto em seu espaço visível mas que, a partir de um trabalho de gênese, pode ser provado como presente. Funda-se assim um paradoxo inaugural em torno da epopeia moderna de Eliot: o entendimento do poema decorreria não de um aprofundamento analítico, mas sim de um recuo interpretativo, de um afastamento que promete um reencontro revelador capaz de desnudar o segredo do poeta e de sua obra.

Ora, não é isso que costumamos presenciar nas análises dos versos iniciais de The Waste Land? "Abril é o mais cruel dos meses, germinando/Lilases da terra morta, 
misturando". ${ }^{1}$ Sabe-se que "a natureza retoma seu eterno ciclo de renascimento e fertilidade, que o 'chuvoso abril' saudado por Chaucer chegou. Mas a primavera aqui não é celebrada" (DREW, 1949, p. 68), ou seja, ao contrário do autor dos Canterbury tales, que saúda a renovação dos ciclos, o poeta da "terra desolada" lamenta o retorno da primavera, parodiando seu antecessor. Seja como for, a satisfação gerada pela alusão reconhecida apenas antecede a angústia de uma eventual referência não identificada. Afinal, e quanto aos "lilases"? Qual a origem que precisa ser aqui esclarecida para o bom entendimento do poema? "The Waste Land é um texto sobre uma crise pessoal e poética, que dissimuladamente toma 'When lilacs last in the dooryard bloom'd', de Walt Whitman, como seu paradigma" (BLOOM, 2003, p. 2). A ideia de uma manobra "dissimulada" é sintomática: há algo que ocorre nos bastidores do poema e que precisa ser elucidado por um crítico munido das ferramentas corretas, nesse caso, o conhecimento da obra de Whitman e das tensões que Eliot mantém com o precursor romântico.

Gostaria, neste breve ensaio, de propor um novo recuo interpretativo, não para evidenciar uma das supostas referências aludidas implícita ou explicitamente por Eliot em The Waste Land, mas antes para investigar justamente o modus operandi desse regime poético que nos faz sempre suspeitar de uma presença dissimulada que, caso trazida à tona, reserva a promessa de nos demover do desconhecimento anterior. Em outras palavras, o ensaio se debruça sobre um dispositivo que insiste na insuficiência daquilo que vemos na superfície do poema e que, por conseguinte, nos desloca repetidamente para um outro espaço em que por fim testemunharíamos a substância real dos versos. Eis o objeto do presente texto. Resulta desse objeto, no entanto, um desconforto que se instala como a própria tese aqui proposta: ao atestar que o leitor lê mas não vê a substância real do poema, ou melhor, ao indicar a circulação de um conteúdo oculto mas que pode ser revelado e exposto a qualquer momento e a partir de um material outro, The Waste Land inaugura para si um campo infinito de atuação, em que um objeto sempre ausente se insinua como promessa de esclarecimento sem nunca se deixar avistar por completo ou satisfazer a expectativa por ele mesmo gerada.

\section{Notas para The Waste Land (I): pressupostos}

Mas, afinal de contas, o que suscita em The Waste Land a sensação de que há ali uma opacidade a ser

\footnotetext{
A tradução do poema de Eliot citada no corpo do texto é de autoria de Ivan Junqueira e está presente no livro: ELIOT, T. S. Obra completa, v. 1 - Poesia. Tradução, introdução e notas de Ivan Junqueira. São Paulo: Arx, 2004. "April is the cruellest month, breeding/Lilacs out of the dead land, mixing" (p. 138).
}

desfeita por meio da leitura apropriada de um material ausente? Afora sua própria composição lacunar - a errância pronominal que desfigura qualquer estabilidade identitária, ou a estrutura paratática que lhe é característica e que interrompe a ordenação lógica dos grupos de versos -, o poema se vale de um campo paratextual discreto, concebido a partir de um outro registro discursivo, para tornar manifesto o trânsito de uma relação intertextual que somente será decodificada por um leitor instruído: refiro-me aqui às célebres "Notas para The Waste Land". Em linhas gerais, a existência desse paratexto silencioso pode ser explicada nos seguintes termos: finalizada a composição de The Waste Land, Eliot submete o poema à revisão de Pound, Il miglior fabbro, conforme a dedicatória que inaugura a obra. Após a exaustiva revisão e os cortes operados pelo mestre, contudo, o poema já não possui o número mínimo de páginas necessário para compor um volume único. Assim, com o intuito inicial de resolver um problema quantitativo - e também para "desarmar os críticos dos poemas anteriores que o tinham acusado de plágio" (ELIOT, 1997, p. 132) -, Eliot adiciona às seções anteriores do poema uma nova subdivisão, intitulada "Notas para The Waste Land". Essa última seção, sob a guarda de uma origem incerta e ocupando as fronteiras do poema - trata-se de fato de uma sexta seção? A quem pertencem as notas, ao poetaautor (Eliot) ou ao mesmo discurso que regula os versos anteriores? -, pretende elucidar as fontes consultadas pelo autor e que determinaram a composição da obra.

Independentemente da imprecisão fundamental que orienta os comentários de Eliot - fato esse que será discutido a seguir -, vale aqui ressaltar o mecanismo de indecidibilidade que resulta do espaço ocupado pelas notas e que abala momentaneamente as próprias fronteiras do poema. Assim, antes de averiguar o valor de verdade das afirmações do poeta, cabe enfrentar uma questão que constitui, por assim dizer, um dilema teórico cuja verificação precede o trabalho de leitura das fontes. Nesse sentido, quando por meio das "Notas para The Waste Land" ficamos sabendo, por exemplo, que "não apenas o título, mas também o plano e o simbolismo incidental do poema, foram sugeridos pelo livro da Srta. Jessie L. Weston sobre a Lenda do Santo Graal: From ritual to romance (Cambridge)" (ELIOT, 2004, p. 168), devemos receber a anotação como uma fala do poema sobre si mesmo e, portanto, como algo necessariamente verdadeiro, já que inapagável? Ou estaríamos diante de um depoimento sobreposto aos versos e que, por lhes ser um objeto externo, torna-se passível de enfrentamento? Nesse último caso, contrariando a hipótese sustentada pela nota, poderíamos muito bem concluir que a leitura de From Ritual to Romance, quando confrontada com os versos de Eliot, aponta uma influência apenas superficial, 
e que, dessa forma, estamos diante de uma leitura precipitada do poema. Isso que a princípio pode parecer um trabalho de policiamento interpretativo é, na verdade, uma operação importante para que o gesto analítico se estruture sobre um entendimento dos reais problemas teóricos impostos pelo texto, ou seja, para que a análise não parta de pressupostos que, embora inconscientes, estabelecem de antemão os limites do exercício crítico.

Em suma, para não resultar um produto parcial das armadilhas estruturais da obra de Eliot, resta ao leitor pronunciar-se sobre uma seção que se situa precisamente nos limites do poema, numa zona desconfortável em que a posição analítica confunde-se com a própria obra, ou melhor, em que a análise faz-se obra e sacraliza um dado procedimento de leitura do que ocorre nos versos. Não por acaso, as "Notas para The Waste Land", como discurso ao mesmo tempo do poema e sobre o poema, estabelecem de modo tácito quais as questões que devem ou não ser examinadas pela crítica, aquilo que o leitor deve ou não fazer diante dos versos, os materiais que ele deve ou não consultar para uma boa performance interpretativa, os personagens que são ou não relevantes etc. Eis a normatividade interna que o poema instaura por apresentar um operador supostamente neutro que distribui as parcelas que cabem aos versos, personagens e seções na análise do leitor instruído. Sem desativar o dispositivo que hierarquiza o conteúdo do poema e determina a operação fundamental do crítico, a leitura de The Waste Land retornará sempre ao seu próprio ponto de partida, isto é, à invisibilidade de uma estrutura que, como tal, controla as partes destinadas ao leitor em sua empresa.

\section{Notas para The Waste Land (II): análise}

Observamos, até o momento, a dificuldade que The Waste Land impõe quanto ao entendimento dos limites que demarcariam seu espaço interno, uma vez que a presença das notas perturba as fronteiras entre o poético e o analítico, entre o dentro e o fora, entre o que pertence e o que não pertence à obra de Eliot. Decorre desse impasse, como visto, um problema interpretativo que desempenha um papel substancial, se não determinante, na atividade do crítico, principalmente quando este ignora a singularidade estrutural da obra que busca investigar. Visto isso, cabe agora analisar até que ponto as "Notas para The Waste Land" realmente cumprem um suposto propósito explicativo, confrontando seu conteúdo com os versos a que se referem. Em poucas palavras, será que as notas materializam uma substância que aparece diluída ao longo do poema e, desse modo, auxiliam o leitor em sua tentativa de reconfigurar o que se faz ali "presente" mesmo sem se anunciar por completo? Ou as notas simplesmente denunciariam um gesto paródico que ironiza o próprio movimento interpretativo por elas incentivado, fragmentando ainda mais o aspecto já fragmentário dos versos (cf. DAVIDSON, 1985, p. 107)? Nesse caso, seria importante investigar o que resulta desse duplo impasse, pois, além de ser um poema "ilimitado", o dispositivo que estimula essa incompletude parece não cumprir o propósito para o qual foi inicialmente projetado, qual seja, a exposição dos implícitos.

$$
* * *
$$

Lado a lado com a formulação lacônica de muitas das notas de Eliot, responsável por conferir pontualidade a referências que se anunciam como autoevidentes "Cf. Ezequiel II, i."; "V. Tristan und Isolde, I, versos 5-8", "Id. III, verso 24" -, caminham as observações menos imediatas e que produzem a cena conflituosa da relação poema/notas. A primeira das "Notas para The Waste Land", por exemplo, institui aquelas que seriam as referências básicas do poema, "capazes de elucidar as dificuldades [interpretativas?] muito melhor do que o poderiam fazer as notas" (ELIOT, 2004, p. 168). Partindo do exame das fontes, e já de saída colocando em questão o alcance explicativo de suas notas, Eliot cita, além do mencionado From ritual to romance, de Jessie L. Weston, o clássico da antropologia intitulado The golden bough, de James George Frazer. Segundo o poeta, "qualquer pessoa suficientemente familiarizada com esses trabalhos reconhecerá de pronto no poema certas alusões a ritos ou cerimoniais relativos à fertilidade" (2004, p. 168).

Ora, mais que um vínculo específico entre determinado elemento do poema e o tratamento que este recebe nas obras de Weston e Frazer, Eliot convida o leitor a um exercício de identificação, de reconhecimento, que somente poderá ser empreendido por quem estiver "suficientemente familiarizado com esses trabalhos". Eis o "dano" constitutivo dessa relação: longe de apresentar um objeto bem definido, as páginas de The golden bough - e o mesmo é verdade para o conteúdo de From ritual to romance - multiplicam-se a ponto de obrigar o antropólogo a publicar uma edição resumida que, mesmo como tal, acumula cerca de novecentas páginas. Nas palavras de Frazer, "a discussão [dos temas do livro] ocupou cada vez mais espaço, até que os dois volumes iniciais da obra deram lugar aos doze atuais. Paralelamente, repetidas vezes anunciou-se o desejo de que o livro fosse publicado em edição resumida" (2002, p. iii). Mas que temas são esses, que obrigam o autor a adiar indefinidamente a conclusão do seu trabalho? The golden bough funciona como uma sorte de enciclopédia mitológica, e assim, "tendo em vista o escopo do mito, fica muito difícil indicar passagens de The Waste Land que não tenham relação alguma [com os livros de Frazer 
e Weston]. Esses livros são feitos da própria matériaprima da literatura" (THORMAHLEN, 1978, p. 198). A primeira nota de Eliot, portanto, produz um movimento circular ao propor que as dúvidas sejam esclarecidas por meio da consulta de dois livros que, em sua composição, assemelham-se a um compêndio sem fim de símbolos comuns a todo e qualquer texto literário. Em busca de paralelos, o leitor está fadado a encontrá-los aos montes.

Mas a função reguladora das notas - daquilo que consuma essa normatividade interna ao poema - não é posta em funcionamento apenas quando o crítico de fato adota a nomenclatura aventada por Eliot - "o objetivo da jornada foi [...], ao propor a questão correta, libertar o Rei Pescador [Fisher King] dos seus males" (SMITH, 1956, p. 74). Com efeito, quando julga o valor de verdade das "Notas para The Waste Land", ou mesmo quando rejeita a presença das referências acusadas pelo poeta na avaliação de Conrad Aiken, "em nenhum desses casos particulares a referência, a alusão, justifica-se ou se faz sentir intrinsecamente" (2004, p. 100) -, o leitor não deixa de proceder a partir das notas, mantendo, pois, a prescrição analítica ali inscrita. Segue disso, inclusive, o caráter paradoxal da presente investigação: para deduzir de The Waste Land a sua estrutura fundamental e desarticular por um momento a aparente neutralidade dos comentários autorais, este texto produz um novo alinhamento entre a sexta seção do poema e a posição da crítica, uma vez que aqui as observações partem sempre, ainda que voluntariamente e num trabalho de desidentificação, da voz autorizada das notas. No fim, o mecanismo só pode ser reconhecido em meio ao seu próprio funcionamento, o que invalida a intenção de atuar às margens das notas; antes, para observar o impasse, faz-se necessário habitar seu centro.

Outra nota de Eliot que compromete a ideia de uma referencialidade velada ora traduzida em observações autorais, estas dispostas ao leitor para a compreensão do poema, diz respeito aos versos 411-416 de The Waste Land: "Dayadhvam: Ouvi a chave / Girar na porta uma vez e apenas uma / Na chave pensamos, cada qual em sua prisão / E quando nela pensamos, nos sabemos prisioneiros / Somente ao cair da noite é que etéreos rumores / Revivem por instantes um alquebrado Coriolano". ${ }^{2}$ Sem se deter em demasia sobre o significado da passagem, o poeta limita-se a citar o filósofo inglês F. H. Bradley, autor de Appearance and reality: "Minhas sensações externas não me são menos privativas do que minhas ideias ou meus sentimentos. Em cada caso, minha experiência se desenvolve dentro do meu próprio círculo,

\footnotetext{
2 "Dayadhvam: I have heard the key / Turn in the door once and turn once only / We think of the key, each in his prison / Thinking of the key, each confirms a prison / Only at nightfall, aetherial rumours / Revive for a moment a broken Coriolanus" (p. 164).
}

um círculo que se fecha no exterior [...]". E ainda: "Em suma, considerado como uma existência que se manifesta em uma alma, o mundo inteiro é, para cada um de nós, peculiar e privativo dessa alma" (apud ELIOT, 2004, p. 173). O excerto de Bradley, confrontado com os versos em pauta e em sua formulação imediata, não poderia ter um significado mais claro: com a passagem, Eliot confirma a interpretação solipsista do poema, segundo a qual a "terra desolada" aprisiona seus indivíduos a quase-experiências que não podem ser comunicadas a outrem ou mesmo compreendidas pelos sujeitos que as vivenciam.

A princípio, a nota está longe de constituir uma faixa de desentendimento no poema; pelo contrário, a sensação que nos passa é a de conforto por ratificar a leitura mais evidente dos versos, embora o faça por meio de uma referência de certo modo a eles estranha. No entanto, dado o próprio estímulo básico de The Waste Land, que nos ensina a todo instante a consultar as fontes ali expostas para uma compreensão integral dos seus problemas interpretativos, o leitor toma Appearance and reality de Bradley como um anexo do poema (mais uma vez, cerca de quinhentas páginas de promessa explicativa) e assim se depara com um novo dilema: se, em meio às linhas de Eliot, o excerto estabelece uma leitura solipsista da "terra desolada", é certo que, em seu contexto original, a passagem está ali em função de um argumento oposto, ou seja, de que haveria sim comunicação entre os sujeitos das experiências. Isso significa, então, que Eliot não compreendeu o tratado do filósofo inglês, valendo-se de uma citação descontextualizada para explicar o conteúdo dos versos 411-416? Que indecisão vemos estabelecida entre o excerto, os versos e o contexto em que Bradley formula sua teoria? Finalmente, devemos agora ignorar as fontes, ou melhor, não ver para poder ver com maior clareza, contrariando o movimento constitutivo das notas e, portanto, do poema?

O elemento que desregula as fronteiras de The Waste Land e destrói a estabilidade de todo um sistema de gêneros - o poema que vira prosa, a prosa que se converte em verso; a análise crítica que se reveste do literário, o literário que transborda para o espaço analítico; enfim, o interno que vaza para além dos seus limites, o externo que se instala ali, no centro dos versos - esse elemento compromete, também, a proposta de uma interpretação intocada pela intenção autoral. Ora, ao invadirmos o espaço biográfico como quem se debruça ainda sobre o poema, tomando-o como extensão evidente do que lhe é interno, notamos que Eliot na verdade conhece muito bem o tratado metafísico de Bradley, bem como o contexto original do excerto destinado aos versos 411-416. Em sua tese de doutoramento, intitulada Knowledge and experience in the philosophy of F. H. Bradley, o 
poeta inclusive elabora um capítulo específico sobre a questão do solipsismo na obra em questão, apenas para concluir o contrário do que sua nota explicativa insinua acerca da passagem. Conforme Louis Menand assinala, "as frases que aparecem na nota de Eliot [...] não representam a posição de Bradley, e certamente não correspondem à posição que o poeta assume em sua tese" (2007, p. 48). A rigor, os problemas acumulam-se a ponto de tornar comprometedora qualquer formulação decorrente da leitura do excerto: por um lado, presos àquela mesma internalidade que o poema não cansa de partir, abraçamos a hipótese solipsista e ignoramos o exercício de interpretação das fontes; por outro, crendo num sistema de traduzibilidade estável das referências, isto é, num sistema idealizado de correspondência entre o que o poema diz e o suposto material a partir do qual ele o faz, abrimos o tratado de Bradley e nos deparamos com um dado que desregula toda uma arquitetura interpretativa até então posta em funcionamento. Em última análise, a saída do dilema demanda a investigação desse centro de dispersão que, ao mesmo tempo, faz convergir para si e invalida as respostas que recebe sobre os falsos problemas que propõe - as "Notas para The Waste Land".

Diante de um poema que se anuncia como um arranjo de fragmentos - "Um feixe de imagens fraturadas", segundo um de seus versos -, a tentativa de organizar as partes (os fragmentos) em torno de um princípio articulador torna-se, no mínimo, um gesto impositivo, para não dizer arbitrário. Pois bem, como um terceiro e último exemplo de como as notas autorais definem as parcelas interpretativas que cabem aos versos para a seguir desarmar a estabilidade da explicação ali gravada, faz-se necessário investigar a observação de Eliot que policia a hierarquização "correta" dos papéis desempenhados pelos episódios de The Waste Land. De acordo com o poeta, por trás da aparente fragilidade identitária dos personagens da "terra desolada" e da fugacidade de sua inscrição no corpo dos versos, haveria, sim, ao longo das cinco seções do poema, uma presença constante, porém de difícil identificação, responsável por agenciar a relação entre as partes e uma totalidade encoberta, mas não ausente:

Tirésias, embora um simples espectador e não propriamente uma 'personagem' [character], é, não obstante, a principal figura [personage] do poema, unificando todo o resto. Assim como o mercador zarolho, vendedor de passas, confunde-se com o Marinheiro Fenício, e este último não é inteiramente distinto de Ferdinando, o Príncipe de Nápoles, assim também todas as mulheres nada mais são do que uma única mulher, e os dois sexos se fundem em Tirésias. O que Tirésias vê é, a rigor, a substância do poema. Toda a passagem em Ovídio é de grande interesse antropológico (ELIOT, 2004, p. 170).
Mais (ou menos) que um personagem, Tirésias, como espectador, vê "a substância do poema" e unifica todas as demais figuras, embora não seja visto como presença imediata ao longo de todas as seções. Em outras palavras, o elemento de unificação proposto por Eliot não é da ordem do sensível, nem tampouco se apresenta como um centro evidente ao leitor desavisado; a bem da verdade, ele unifica o resto apesar de, apesar de se manifestar de modo tímido no corpo do poema, ocupando apenas cerca de 40 versos de um total de 434. Abaixo segue o fragmento da terceira seção do poema, intitulada "The fire sermon", em que Tirésias aparece de modo pontual e pode ser visto como presença efetiva:

$\mathrm{Eu}$, Tirésias, embora cego, palpitando entre duas vidas, Um velho com as tetas engelhadas, posso ver, Nessa hora violácea, o momento crepuscular que luta Rumo ao lar, e que devolve o marinheiro à sua casa; A datilógrafa que regressa ao lar à hora do chá,

Recolhe as sobras do café da manhã, acende

$\mathrm{O}$ fogareiro e improvisa ser jantar em latas de conserva. Suspensas perigosamente na janela, suas combinações Secam ao toque dos últimos raios solares.

Sobre o divã (à noite, sua cama) empilham-se

Meias, chinelos, batas e sutiãs.

Eu, Tirésias, um velho de tetas enrugadas,

Percebo a cena e antevejo o resto.

- Também eu aguardava o esperado convidado.

Chega então um rapaz com marcas de bexiga,

Um insignificante balconista de olhar atrevido,

Um desses tipos à-toa em que a arrogância assenta tão bem

Quanto a cartola na cabeça de um milionário de Bradford.

O momento é agora propício, ele calcula,

O jantar acabou, ela está exausta e entediada.

Ele procura então envolvê-la em suas carícias,

Não de todo repelidas, mas tampouco desejadas.

Excitado e resoluto, ele afinal investe.

Mãos aventureiras não encontram resistência;

Sua vaidade dispensa resposta,

E faz da indiferença uma dádiva.

(E eu, Tirésias, que já sofrera tudo

O que fora ensinado nessa cama ou divã,

Eu que me sentei ao pé dos muros de Tebas

E caminhei por entre os mortos mais sepultos.)

Ao despedir-se, concede-lhe o rapaz um beijo protetor

E desce a escada escura, tateando o caminho... ${ }^{4}$

\footnotetext{
3 "A heap of broken images" (p. 138).

4 "I Tiresias, though blind, throbbing between two lives, / Old man with wrinkled female breasts, can see / At the violet hour, the evening hour that strives / Homeward, and brings the sailor home from sea, / The typist home at tea-time, clears her breakfast, lights / Her stove, and lays out food in tins. / Out of the window perilously spread / Her drying combinations touched by the sun's last rays, / On the divan are piled (at night her bed) / Stockings, slippers, camisoles, and stays. / I Tiresias, old man with wrinkled dugs / Perceived the scene, and foretold the rest - / I too awaited the expected guest. / He, the young man carbuncular, arrives, / A small house-agent's clerk, with one bold stare, / One of the low on whom assurance sits / As a silk hat on a Bradford millionaire. / The time
} 
Como se pode ver, a cena vislumbrada por Tirésias diz respeito a um encontro sexual mecanizado. Contudo, para além da passagem em específico e de seu conteúdo pontual, ali onde o vidente não está, segundo Eliot, ele também está, ao contrário dos demais personagens, que se limitam a aparecer num dado momento para então sair de cena. Madame Sosostris, por exemplo, a vidente que surge na primeira seção de The Waste Land, numa faixa de 17 versos - mas cuja previsão atravessa e, até certo ponto, "controla" todas as seções do poema -, não é capaz de unificar as demais figuras; pelo contrário, é o olhar de Tirésias, que ali não está presente mas está, que a faz convergir para um centro maior de articulação. Resta-nos, seguindo esse cálculo, responder à inevitável questão: como o poema pode tornar-se uno através de um agente unificador, por assim dizer, "invisível"?

Como era de esperar, a vagueza da pergunta e a falta de concretude do seu objeto dão margem a uma ampla gama de respostas, todas a princípio consistentes, ainda que irreconciliáveis entre si: "[A nota sobre Tirésias] oferece a pista para The Waste Land. Ela indica de forma bastante clara o que o poema é: uma tentativa de enfocar uma consciência humana inclusiva" (LEAVIS, 1960, p. 95); “'Eu Tirésias' é a única identificação explícita da voz [speaker] do poema, e há uma razão para isso" (WILLIAMSON, 1957, p. 142.); "É possível dizer que a voz [speaker] aqui e em todo o poema é a de Tirésias, mas isso é como dizer que algo é a voz de Deus - apenas substituímos um problema por outro" (DONOGHUE, 2000, p. 121); "[A nota de Eliot sobre Tirésias] nos ajuda a concluir que a substância do poema é a escravidão do homem ao sexo e suas consequências" (GEORGE, 1969, p. 148). “A atribuição da substância do poema ao ponto de vista de Tirésias é um alerta de que o poema não possui uma unidade substancial de qualquer outro tipo" (BROOKER e BENTLEY, 1990, p. 55). As diferentes posições assumidas em torno da figura de Tirésias em The Waste Land não assinalam equívocos de leitura, apenas demonstram que há uma regra inscrita no poema que nos induz a receber e discutir o profeta sob certo ângulo - a partir, inclusive, de um dado campo conceitual, em que se destacam termos como "centralidade", substância"-, isso quer concordemos ou não com a leitura prescrita. Afinal, será que a discussão dar-se-ia nesses mesmos termos sem a nota autoral?

\footnotetext{
is now propitious, as he guesses, / The meal is ended, she is bored and tired, / Endeavours to engage her in caresses / Which still are unreproved, if undesired. / Flushed and decided, he assaults at once; / Exploring hands encounter no defence; / His vanity requires no response, / And makes a welcome of indifference. / (And I Tiresias have foresuffered all / Enacted on this same divan or bed; / I who have sat by Thebes below the wall / And walked among the lowest of the dead.) / Bestows one final patronizing kiss, / And gropes his way, finding the stairs unlit..." (p. 152-154).
}

Se parece evidente que a recepção de Tirésias é conceitualmente controlada pela atuação discreta das "Notas sobre The Waste Land", vale ainda notar que, mesmo levada a cabo em sua dimensão referencial, a observação de Eliot sobre o profeta tebano não deixa de produzir um efeito circular sobre a interpretação do leitor. Esse centro unificador em parte ausente do corpo do poema repete em sua constituição física a ideia de uma identidade absoluta porém esvaziada de qualquer conteúdo específico e, nesse sentido, de fácil reabsorção referencial. Em outras palavras, Tirésias pode ser associado a qualquer verso de The Waste Land, não por expressar uma matéria particular que de fato atravessa todas as seções do poema, mas sim por manifestar, ele próprio, uma lacuna a ser preenchida pelos próprios versos que a ele fazemos convergir.

Mas que constituição física seria essa, absoluta apenas em sua abertura? Como visto, em The Waste Land Tirésias é descrito como alguém que, "embora cego, palpitando entre duas vidas, / Um velho com tetas engelhadas", pode ver, ou seja, um cego que vê mais que todos e que habita uma zona de fronteira entre os dois sexos. Não bastasse a oscilação identitária inicial Tirésias não é nem homem nem mulher, mas uma mistura de ambos -, o vidente, conforme os relatos mitológicos expõem, é um velho que terá de viver por muitos anos, e assim, graças a essa longevidade, está condenado a um eterno retorno. Velho, porém "jovem", homem, mas também mulher, cego que pode ver: por um lado, que personagem em The Waste Land deixará de apresentar vínculos com uma tal figura híbrida? Por outro, que aparição verá sua singularidade explicada a partir de um composto de identidades provisórias? No fim das contas, ponto de chegada e ponto de partida confundem-se de tal modo que somente silenciando o poema em seu deslocamento essencial é que o leitor poderá propor sua tese sobre o papel unificador de Tirésias, o centro ausente.

\section{Notas para The Waste Land (III): implicações finais}

Limitamo-nos aqui a três exemplos, que gravitam em torno de Frazer, Bradley e Tirésias, mas é certo que o aspecto fugidio das notas de Eliot é uma regra, não exceção. Para além dos casos citados, poderíamos acentuar, dentre outros, o tom acidental que marca várias das observações do poeta, como se as notas devessem ser tomadas como um gesto casual e incapaz de exercer qualquer efeito sobre a interpretação do poema: "não estou bem a par da exata constituição do baralho de cartas do Tarot, das quais me utilizei como um ponto de partida e [...] segundo minhas próprias conveniências" (2004, p. 168); "desconheço a origem da balada de que foram 
extraídos estes versos; foram-me reportados de Sydney, Austrália" (p. 170); "pode não parecer tão exato quanto os versos de Safo, mas eu tinha em mente o pescador 'litorâneo' ou aquele que sai ao mar em sua pequena 'dóri', regressando ao anoitecer" (p. 171); por fim, “os versos que se seguem foram inspirados pelo relato de uma das expedições à Antártica (não me recordo qual, mas suponho que uma das que realizou Shackleton)" (p. 172). "Não estou bem a par", "desconheço", "pode não parecer tão exato", "não me recordo qual": se o intuito das notas é explicar, Eliot parece fazê-lo, em dados momentos, por meio de um impressionismo pouco pontual, mas que, colado às demais observações - estas sim lacônicas e munidas de uma erudição livresca -, convida o leitor à atividade de identificação e administração correta das referências.

Há nesse jogo das fontes, no deslizamento constante de um espaço a outro - dos versos às notas, das notas às referências, das referências aos versos -, algo que podemos chamar de uma poética do desentendimento. Em vez de um esclarecimento paulatino, condicionado à conquista do material que supostamente originou The Waste Land, Eliot prova estar muito mais interessado na produção de uma cena polêmica que impossibilita a interpretação consensual do poema e que, por isso mesmo, agencia uma máquina de teses. Segundo o testemunho de um de seus críticos mais importantes, F. O. Matthiessen, Eliot concebia o desentendimento [misunderstanding] como um princípio de leitura, um procedimento capaz de reconfigurar a produção poética de um dado momento. Não por acaso, ainda de acordo com Matthiessen, o poeta tinha o intuito de redigir um livro sobre $A$ riqueza do desentendimento [The fruitfulness of misunderstanding], em que abordaria "várias das mudanças significativas que ocorrem na poesia quando um autor, ao tentar imitar um outro, compreende equivocadamente seu modelo e cria algo novo" (apud MENAND, 2007, p. 93). O objetivo do livro não seria remediar os desvios da análise, como tanto insistiram os new critics, mas sim investigar os instantes de pane interpretativa e os ruídos produtivos deles resultantes, isso sob uma perspectiva histórica.

O projeto de Eliot não chegou a ser concretizado como tal. No entanto, por conta dos vários curto-circuitos interpretativos que provoca na zona de articulação entre notas e versos, The Waste Land pode ser lido justamente como essa máquina de desentendimento, que demove as hierarquias dos gêneros e das referências para inaugurar um espaço plural. E as teses que os leitores não deixam de lançar sobre o poema - acerca dele e, de fato, sobre ele, sobre sua mobilidade primeira e de modo a freá-la -, em última instância, apenas renovam o funcionamento da maquinaria e dão mostras de sua potência desreguladora.

\section{Referências}

AIKEN, Conrad. An anatomy of melancholy. In: BROOKER, Jewel Spears (Ed.). T. S. Eliot: the contemporary reviews. New York: Cambridge University Press, 2004. p. 99-103.

BLOOM, Harold (Ed.). Bloom's biocritiques: T. S. Eliot. New York: Chelsea House Publishers, 2003.

BROOKER, Jewel Spears; BENTLEY, Joseph. Reading The waste land: modernism and the limits of interpretation. Massachusetts: The University of Massachusetts Press, 1990.

DAVIDSON, Harriet. T. S. Eliot and hermeneutics: absence and interpretation in The Waste Land. Baton Rouge: Louisiana State University Press, 1985.

DONOGHUE, Denis. Words alone: the poet T. S. Eliot. New Haven \& London: Yale University Press, 2000.

DREW, Elizabeth. T. S. Eliot: the design of his poetry. New York: Charles Scribner's Sons, 1949.

ELIOT, T. S. Ensaios de doutrina crítica. Tradução de Fernando de Mello Moser. 2. ed. Lisboa: Guimarães Editores, 1997.

ELIOT, T. S. Obra completa: v. I - Poesia. Tradução, introdução e notas de Ivan Junqueira. São Paulo: Arx, 2004.

FRAZER, James George. The golden bough: a study in religion and magic. New York: Dover Publications, Inc., 2002.

GEORGE, A. G. T. S. Eliot: his mind and art. 2. ed. New York: Asia Publishing House, 1969.

LEAVIS, F. R. New bearings in English poetry: a study of the contemporary situation. Ann Arbor: The University of Michigan Press, 1960

MENAND, Louis. Discovering Modernism: T. S. Eliot and his context. 2. ed. New York: Oxford University Press, 2007.

SMITH, Grover. T. S. Eliot's poetry and plays: a study in sources and meaning. Chicago and London: The University of Chicago Press, 1956.

THORMAHLEN, Marianne. The waste land: a fragmentary wholeness. Lund: LiberLaromedel/Gleerup, 1978.

WILLIAMSON, George. A reader's guide to T. S. Eliot: a poem by poem analysis. New York: The Noonday Press, 1957.

Recebido: 13 de abril de 2014

Aprovado: 07 de junho de 2014

Contato: andrecechinel@gmail.com 